Himalayan J. Soc. Sci. \& Humanities ISSN: 0975-9891

Vol. 14, (2019) 45-50

DOI: https://doi.org/10.51220/hjssh.v14i1.7

\title{
Government Policies And Implementation For Sugarcane Production In Western Uttar Pradesh: A Review
}

\section{Prashant Kandari and Rajeev Kumar}

Department of Economics, H N B Garhwal University Srinagar Garhwal-246174, Uttarakhand

*Corresponding Author Email: kandari1980@gmail.com

Received: 17.10.2019; Revised: 19.11.2019; Accepted: 2.12.2019

CSociety for Himalayan Action Research and Development

\begin{abstract}
India is the original place of sugarcane production. Sugar cane is used to prepare sugar and its other forms in India. In 1920, the then Governor General of India established the Indian Sugar Committee, wishing a bright future for the business of sugar. In the year 1930, a Tariff Board was established on the recommendation of the sub-Committee of the Research Council of India. In this, the Government of India was recommended to protect the sugar industry. Though in Pratappur, UP, India's first sugar mill was established, yet the farmers were facing numerous problems due to lack of installed system. The Government of India passed Sugar cane act 1934 and through which authorised state Governments to control prices of sugar manufactured by different sugar mills. In Uttar Pradesh, the Department of Sugar Development was established in 1935. The paper discusses the policies and their implementation in the field of sugar production.
\end{abstract}

Keywords: Sugar cane, Industry, Government Policy, Implementation, Analysis

\section{पश्चिमी उत्तर प्रदेश में गन्ना उत्पादन हेतु सरकार की शासकीय नीतियां एवं परिपालनः एक समीक्षात्मक अध्ययन}

\author{
प्रशान्त कण्डारी एवं राजीव कुमार \\ अर्थशास्त्र विभाग, बिडला परिसर, हे० न० ब० ग० विवि श्रीगर गढवाल, उत्तराखण्ड 246174
}

*Corresponding Author Email: kandari1980@gmail.com

Received: 17.10.2019; Revised: 19,11,2019; Accepted: 2.12 .2019

(C)Society for Himalayan Action Research and Development

\section{सारांश}

गन्ने का मूल स्थान भारत वर्ष है। प्राचीन काल से ही भारत में गन्ना, गुड़ व राव बनाने के काम में आता था। सन 1920 में भारत के तत्कालीन गवर्नर जनरल ने चीनी व्यवसाय के उज्जवल भविष्य की कल्पना करते हुए "इंडियन शुगर कमेटी" की स्थापना की थी। सन 1930 में भारतीय कृषि अनुसंधान परिषद की गन्ना उप समिति की सिफारिश पर एक "टैरिफ बोर्ड" की स्थापना की गई, जिसने भारत सरकार से चीनी उद्योग को आरंभ कें 15 वर्षों के लिए संरक्षण देने 
Himalayan J. Soc. Sci. \& Humanities ISSN: 0975-9891

Vol. 14, (2019) 45-50

की सिफारिश की गई। जिस कारण से भारत में सन 1931 में चीनी उद्योग को संरक्षण प्रदान किया गया। उत्तर प्रदेश में यद्यपि देवरिया के प्रतापपुर नामक स्थान पर 1903 में ही भारत की प्रथम प्राचीनतम चीनी मिल स्थापित हो चुकी थी। परंतु गन्ना विक्रय की कोई संस्थापित पद्धति के अभाव में गन्ना कृषकों को अनेकों समस्याओं का सामना करना पड़ता था। भारत सरकार द्वारा पारित "शुगरकेन एक्ट 1934" द्वारा प्रदेशीय सरकारों को किसी क्षेत्र को नियंत्रित करते हुए वैक्यूम पैन चीनी मिलों द्वारा प्रयुक्त होने वाले गन्ने के न्यूनतम मूल्य निर्धारित करने के लिए अधिकृत किया गया उउत्तर प्रदेश में सन 1935 में गन्ना विकास विभाग स्थापित हुआ। सरकार ने गन्ना कृषकों की सहायता की दृष्टि से "शुगर फैक्ट्री एक्ट 1938" लागू किया गया।

प्रस्तावना- गन्ना भारत की मुख्य नकदी फसल है जो उत्पादन व उपभोग दोनो की दृष्टि से अति महत्वपूर्ण फसल है तथा भारत वर्तमान में विश्व में प्रथम स्थान पर गन्ना उत्पादन कर रहा है। भारत में कुल उत्पादित चीनी का लगभग 80 प्रतिशत भाग गन्ने से तैयार किया जाता है और चीनी का 20 प्रतिशत भाग चकून्दर से तैयार किया जाता है। भारत में उत्तर प्रदेश राज्य प्रथम स्थान पर गन्ने का उत्पादन कर रहा है और भारतीय आय में लगभग 2.5 प्रतिशत भाग की भागीदारी अकेले उ०प्र० राज्य निभा रहा है। भारत में कृषि उत्पादन हेतु कृषक मौसम पर निर्भर है जिससे उसको अत्यधिक हानि उठानी पडती है। भारत में कृषको के पास अति छोटी भूमि जोते है जिससे उनको उत्पादन बढाने में विभिन्न समस्याओ का सामना करना पडता है। जैसे अधिक ऋण का बोझ, अधिक ब्याज दर, तथा ऋण लेने में भी अत्यधिक समस्याओ का सामना करना पडता है। पश्चिमी उ०प्र० में गन्ना कृषक गन्ना उत्पादन में महत्वपूर्ण भूमिका निभाते है तथा सरकार कृषको को समय-2 पर विभिन्न प्रकार की सुविधाये उपलब्ध कराती है इसलिए सरकार कि उन नीतियो का अध्ययन करना अति आवश्यक है।

उद्देश्य :- 1 सरकार द्वारा दी जाने वाली शासकीय नीतियो का अध्ययन करना।

2 गन्ना उत्पादन में शासकीय नीतियो की सहायता का मुल्यांकन ज्ञात करना।

शोध विधि :- शोध क्षेत्र में उत्तर प्रदेश के दो जनपदो हापुड़ व मेरठ को लिया गया है। जनपद हापुड़ व मेरठ में क्रमशः 4 व 12 विकास खण्ड हैं। जिनमें से दैव न्यादर्श विधि से हापुड़ जिले के 2 विकास खण्ड तथा मेरठ जनपद से 4 विकास खण्डो को लिया गया है। प्रत्येक ब्लॉक से 2-2 गाँव लिये गऐ है और प्रत्येक गाँव से 30 कृषक परिवारो का चयन किया गया है। प्रत्येक स्तर पर न्यादर्श का चुनाव दैव न्यादर्श विधि के आधार पर किया गया है। इस प्रकार प्रस्तुत शोध में कुल 360 कृषक परिवारों का अध्ययन किया गया है।

शोध अध्ययन प्राथमिक एवं द्वितीयक तथ्यों पर आधारित है। प्राथमिक आकड़ों का संकलन साक्षात्कार अनुसूची व अवलोकन के माध्यम से किया गया है। द्वितीयक आकड़ो का संकलन सम्बन्धित पुस्तकों, गैर सरकारी रिपोर्ट, सरकारी रिपोर्ट, एन०जी०ओ० रिपोर्ट, सम्बन्धित व्यक्तियों के अनुभव आदि से संकलित किया गया है

अध्ययन का महत्व- प्रस्तुत अध्ययन से वस्तुतः गन्ना विकास को सापेक्ष रूप में समझने एवं उत्पादन में बाधक तत्वों को दूर करने हेतु नये सुझावों व उपायों के निर्माण में सहायता मिलेगी व पश्चिमी उ० प्र० में गन्ना कृषि के सन्दर्भ में विकास व नयी नीतियो के आयामों को स्थापित करने में सहायक सिद्ध होगी। जिससे कृषकों की सामाजिक व आर्थिक स्थिति में सुधार आयेगा। शोध अध्ययन द्वारा प्राप्त निष्कर्षों से कृषि उत्पादन हेतु ऋण प्राप्ति, ब्याज दर और इनसे उत्पन्न होने वाली समस्याओ के निवारण के लिए नियोजित नीतिगत ढाचा बनाने हेतु सहायता मिलेगी तथा उनकी समस्याओं के निदानो हेतु सुझाव दिया जायेगा।

गन्ना उत्पादन हेतु सरकार द्वारा शोध क्षेत्र में चलाई जा रही शासकीय नीतिया-

गन्ना के उतपादन को बढाने के लिए सरकार विभिन्न प्रकार की नीतियों को क्षेत्र में चला रही है और गन्ना कृषक परिवारो को आर्थिक व सामाजिक लाभ देने की लगातार प्रयास कर रही है। 
खाद, दवाई व यंत्र वितरण योजना।

$>$ कृषकों को समिति ऋण वितरण योजना।

$>$ नाबार्ड से प्राप्त धनराशियों के वितरण की योजना।

$>$ अनुदान वितरण की योजना।

$>$ लाभांश वितरण की योजना।

$>$ पौधशाला वितरण की योजना।

$>$ गन्ना बीज वितरण की योजना।

$>$ कृषकों के गन्ने का सर्वे सट्टा अतिरिक्त सट्टा एवं पर्ची वितरण योजना।

गन्ना उत्पादन हेतु सरकार शोध क्षेत्र में विभिन्न प्रकार की नीतियो को चला रही है जैसे खाद, दवाई व यंत्र वितरण योजना, कृषकों को समिति ऋण वितरण योजना, नाबार्ड से प्राप्त धनराशियों के वितरण की योजना, अनुदान वितरण की योजना, लाभांश वितरण की योजना, पौधशाला वितरण की योजना, गन्ना बीज वितरण की योजना कृषकों के गन्ने का सर्वे सट्टा अतिरिक्त सट्टा एवं पर्ची वितरण योजना आदि योजनाओ के द्वारा सरकार गन्ने के उत्पादन में वृद्वि हेतु कृषको की आर्थिक व सामाजिक स्थिति को सुधारने का प्रयास कर रही है।

1. गन्ना उत्पादन हेतु सरकारी नीतियो द्वारा लाभान्वित कृषक परिवार :- प्रस्तुत तालिका में सरकारी द्वारा क्षेत्र में चलायी जाने वाली शासकीय नीतियो से लाभान्वित होने वाले गन्ना कृषकों को दर्शाया गया है। कि किस प्रकार से गन्ना कृषक परिवार सरकार के द्वारा चलायी जाने वाली योजनाओ से अपनी फसलो का उत्पादन को बढाने में कुछ सीमा तक सफल हो रहे है। जबकि शोध क्षेत्र के अन्तर्गत अभी भी कुछ कृषक परिवारो को उपरोक्त योजनाओ का किसी भी प्रकार से लाभ नही मिल पा रहा है।

तालिका 1.1 में सरकार की शासकीय नीतियो से लाभान्वित तथा लाभ न प्राप्त करने वाले कृषक परिवारो को दर्शाया गया है। तालिका से स्पष्ट है कि शोध क्षेत्र के अंतर्गत लगभग 38 प्रतिशत कृषक परिवारों को सरकार द्वारा दी जा रही योजनाओं का लाभ मिल रहा है तथा 62 प्रतिशत कृषक परिवारों को योजनाओं का लाभ नहीं मिल पा रहा है। अतः अध्ययन से स्पष्ट है कि शोध क्षेत्र में कुल 62 प्रतिशत कृषक परिवारो को सरकार की नीतियो का कोई लाभ नही मिल पा रहा है। इस प्रकार क्षेत्र में गन्ना कृषक परिवारो को सरकार की गन्ना उत्पादन हेतु नीतियो के प्रति जागरूक करने की अति आवश्यकता है।

\section{तालिका 1. गन्ना उत्पादन हेतु सरकारी नीतियो द्वारा लाभान्वित कृषक परिवार}

\begin{tabular}{|l|l|l|}
\hline गन्ना उत्पादन हेतु सरकारी नीतियो द्वारा लाभान्वित कृषक परिवार \\
\hline लाभान्वित कृषक परिवार & उत्तादाताओ की संख्या & प्रतिशत \\
\hline ळां & 136 & 37.8 \\
\hline न्ही & 224 & 62.2 \\
\hline कुल संख्या & 360 & 100 \\
\hline
\end{tabular}

स्त्रोतः प्राथमिक सर्वेक्षण (2016-2017)

2. गन्ना उत्पादन हेतु सरकारी नीतियो के प्रकार :- इस तालिका में सरकार द्वारा गन्ने के उत्पादन हेतु शोध क्षेत्र में बीज, उर्वरक खाद, रसायन खाद, आदि योजनाओ से लाभान्वित कृषक परिवारों को दर्शाया गया है कि गन्ना मिल व सरकार के द्वारा इन नीतियो का किस प्रकार से गन्ना कृषक परिवारो को लाभ मिल रहा है और कितने 
Himalayan J. Soc. Sci. \& Humanities ISSN: 0975-9891

Vol. 14, (2019) 45-50

ऐसे कृषक परिवार है जिन्हे सरकार द्वारा दी जाने वाली योजनाओ का लाभ नही मिल रहा है। तलिका 1.2 में गन्ना उत्पादन बढाने हेतु गन्ना कृषक परिवारो के लिए बीज, उर्वरक खाद, रसायन खाद, आदि योजनाओ के आवंटन को दर्शाया गया है। तालिका से स्पष्ट है कि शोध क्षेत्र के अंतर्गत कृषक परिवारों को विभिन्न योजनाओं का लाभ मिल रहा है। लगभग 10 प्रतिशत कृषक परिवारों को गन्ना बीज, 11 प्रतिशत कृषक परिवारों को उर्वरक खाद, लगभग 4 प्रतिशत गन्ना कृषक परिवारों को कृषि रसायन तथा शोध क्षेत्र में कुल 17 प्रतिशत कृषक परिवारों को उपरोक्त सभी योजनाओं का लाभ मिल रहा है। शोध क्षेत्र में लगभग कुल 48 प्रतिशत कृषक परिवारों को किसी भी योजना का लाभ मिल रहा है जबकि शोध क्षेत्र में 58 प्रतिशत कृषक परिवारों को योजनाओं के विषय में जानकारी ही नहीं है और ना ही इन कृषक परिवारो को उपरोक्त सरकार द्वारा दी जाने वाली योजनाओ का कोई भी लाभ मिल रहा है।

\section{तालिका 2. गन्ना उत्पादन हेतु सरकारी नीतियां}

\begin{tabular}{|l|l|l|l|}
\hline गन्ना उत्पादन हेतु सरकारी नीतियो के प्रकार \\
\hline क्रम संख्या & सरकारी नीतियो के प्रकार & उत्तादाताओ की संख्या & प्रतिशत \\
\hline 1 & बिज & 35 & 9.7 \\
\hline 2 & उर्वरक खाद & 40 & 11.1 \\
\hline 3 & रसायन & 14 & 3.9 \\
\hline 4 & उपरोक्त सभी & 61 & 16.9 \\
\hline & कुल लाभान्वित कृषक & 150 & 41.7 \\
\hline कृषक परिवार जिन्हे लाभ नही मिल रहा है & 210 & 58.3 \\
\hline कुल संख्या & 360 & 100 \\
\hline
\end{tabular}

स्त्रोतः प्राथमिक सर्वेक्षण (2016-2017)

अतः अध्ययन से स्पष्ट है कि सरकार द्वारा दी जा रही योजनाओं का लाभ मात्र 42 प्रतिशत कृषक परिवारों को मिल रहा है तथा शोध क्षेत्र 58 प्रतिशत कृषक परिवारों को योजनाओं के विषय में कोई जानकारी ही नहीं है और ना ही इन कृषक परिवारो को उपरोक्त सरकार द्वारा दी जाने वाली योजनाओ का कोई भी लाभ मिल रहा है। इस प्रकार शोध क्षेत्र में गन्ना कृषक परिवारो को सरकार व गन्ना मिल द्वारा दी जाने वाली योजनाओ के विषय में जागरूक करने की अति आवश्यकता है।

3. सरकारी योजनाओं का जातिवार वितरण :- शोध क्षेत्र में जातियो में विभिन्नता होने के कारण से बहुत सी जातियो में सरकार व गन्ना मिल द्वारा चलायी जाने वाली नीतियो का लाभ नही मिल पाता है इसलिए विभिन्न प्रकार की योजनाओ को जातिगत दर्शाया गया है कि किस जाति क्षेत्र में सरकारी नीतियो का अधिक व कम लाभ मिल पा रहा है तथा किस जाति विशेष के अंतर्गत किस योजना का लाभ पहुँच ही नही रहा है।

निम्नलिखित तालिका में सरकार व गन्ना मिल के द्वारा गन्ना उत्पादन हेतु कृषक परिवारो को दी जाने वाली योजनाओ के लाभ को जातिगत दर्शाया गया है।उपरोक्त तालिका से स्पष्ट है कि गन्ना बीज उत्पादन योजना का 26 प्रतिशत सामान्य जाति, 21 प्रतिशत पिछड़ी जाति, व 25 प्रतिशत अनुसूचित जाति को लाभ प्राप्त हो रहा है। उर्वरक खाद योजना का लाभ 23 प्रतिशत सामान्य जाति, 26 प्रतिशत पिछड़ी जाति, और 29 प्रतिशत अनुसूचित जाति को लाभ मिल रहा है। कृषि रसायन योजना का 6 प्रतिशत सामान्य जाति, 10 प्रतिशत पिछड़ी जाति और 10 प्रतिशत अनुसूचित जाति को लाभ मिल रहा है तथा उपरोक्त सभी योजनाओ का कुल 15 प्रतिशत सामान्य जाति, 29 प्रतिशत पिछडी जाति व 17 प्रतिशत अनुसूचित जाति के कृषक परिवारो को लाभ प्राप्त हो रहा है। 
Himalayan J. Soc. Sci. \& Humanities ISSN: 0975-9891

Vol. 14, (2019) 45-50

\section{तालिका 3. सरकारी योजनाओं का जातिवार वितरण}

\begin{tabular}{|c|c|c|c|c|c|}
\hline \multicolumn{6}{|c|}{ सरकारी योजनाओं का जातिवार वितरण } \\
\hline & & \multicolumn{3}{|l|}{ जतियां } & \multirow{2}{*}{$\begin{array}{l}\text { कुल लाभार्थियो } \\
\text { की संख्या }\end{array}$} \\
\hline & & सामान्य जाति & पिछडी जाति & अनुसूचित जाति & \\
\hline \multirow{4}{*}{ सरकारी नीतियो के प्रकार } & बिज & \begin{tabular}{|ll}
9 & $(26.47)$
\end{tabular} & $14 \quad(20.59)$ & $12 \quad(25)$ & 35 \\
\hline & उर्वरक खाद & $\begin{array}{ll}8 & (23.52)\end{array}$ & $18 \quad(26.47)$ & $14 \quad(29.17)$ & 40 \\
\hline & रसायन & $2(5.88)$ & $7 \quad(10.29)$ & $\begin{array}{ll}5 & (10.41)\end{array}$ & 14 \\
\hline & उपरोक्त सभी & $15 \quad(44.11)$ & $29 \quad(42.64)$ & $17 \quad(35.41)$ & 61 \\
\hline \multicolumn{2}{|l|}{ कुल लाभार्थियो की संख्या } & 34 & 68 & 48 & 150 \\
\hline
\end{tabular}

स्त्रोतः प्राथमिक सर्वेक्षण (2016-2017)

अध्ययन से स्पष्ट है कि सभी योजनाओं का 44 प्रतिशत सामान्य जाति, 43 प्रतिशत पिछड़ी जाति, व 35 प्रतिशत अनुसूचित जाति के कृषक परिवारों को लाभ मिल रहा है। कुल योजनाओ के लाभ में सामान्य जाति के कृषक परिवारो का प्रतिशत अन्य जातियो से कम है। अतः शोध क्षेत्र में गन्ना कृषको को जागरूक व सरकार और गन्ना मिल द्वारा दी जाने वाली योजनाओ के लाभ के आवंटन को उचित रूप से करने की आवश्यकता है।

4. गन्ना मिल द्वारा प्रदान की जाने वाली सुविधाएं :- शोध क्षेत्र में गन्ना उत्पादन हेतु गन्ना मिल के द्वारा कृषक परिवारो को कुछ विशेष प्रकार की नीतियां जैसे गन्ना बीज, उर्वरक खाद, रसायन खाद, गन्ना उत्पादन हेतु भूमि पर ऋण, आदि उपलबध करायी जा रही है। निम्नलिखित तालिका में गन्ना कृषकों को मिल द्वारा प्रदान की जाने वाली विभिन्न नीतियो के लाभ को कृषक परिवारो में दर्शाया गया है।

\section{4. गन्ना मिल द्वारा प्रदान की जाने वाली सुविधाएं}

\begin{tabular}{|l|l|l|l|}
\hline गन्ना मिल द्वारा प्रदान की जाने वाली सुविधाएं \\
\hline कम संख्या & नीतियो के प्रकार & उत्तादाताओ की संख्या & प्रतिशत \\
\hline 1 & गन्ना बीज & 69 & 19.2 \\
\hline 2 & उर्वरक खाद & 63 & 17.5 \\
\hline 3 & रसायन खाद & 57 & 15.8 \\
\hline 4 & भूमि पर ऋण & 35 & 9.7 \\
\hline 5 & उपरोक्त सभी सुविधायें & 105 & 29.2 \\
\hline 6 & कुल लाभार्थि कृषक & 329 & 91.4 \\
\hline 7 & संवय कृषि करने वाले कृषक & 31 & 8.6 \\
\hline कुल कृषक परिवारो की संख्या & 360 & 100 \\
\hline
\end{tabular}

\section{स्त्रोतः प्राथमिक सर्वेक्षण (2016-2017)}

उपरोक्त तालिका से स्पष्ट है कि 19 प्रतिशत गन्ना कृषक परिवारों को गन्ना बीज, 17 प्रतिशत कृषक परिवारों को उर्वरक खाद, 16 प्रतिशत गन्ना कृषक परिवारों को कृषि रसायन, लगभग 10 प्रतिशत कृषक परिवारों को भूमि पर ऋण तथा 29 प्रतिशत कृषक परिवार उपरोक्त सभी सुविधाएं प्राप्त करने में सफल हो पा रहे है तथा सभी योजनाओ का भिन- भिन प्रकार से लाभ प्राप्त करने वाले सभी कृषक परिवार मात्र 91 प्रतिशत है जबकि शोध क्षेत्र 
में मात्र 8.6 प्रतिशत कृषक परिवार ऐसे है जो गन्ना मिल द्वारा मिलने वाली किसी भी योजना का लाभ नही प्राप्त करते है। अतः अध्ययन से स्पष्ट है कि गन्ना मिल द्वारा प्रदान की कराई जा रही सुविधाओं का लाभ 91 प्रतिशत कृषक परिवारों को मिल रहा है। और लगभग 9 प्रतिशत कृषक परिवारों को इस सुविधाओं की जानकारी नहीं है या वे स्वंय कृषि करने में सक्षम है परन्तु ये कृषक परिवार किसी भी प्रकार का कोई लाभ प्राप्त नही करते है।

निष्कर्ष :- शोध क्षेत्र में गन्ना कृषको की समस्याओ का अध्ययन किया गया है तथा अध्ययन से निम्नलिखित तथ्य स्पष्ट होते है। सरकार व गन्ना मिल द्वारा प्रदान की जाने वाली योजनाओं का विवरण निम्न प्रकार है :-

शोध क्षेत्र में सभी योजनाओं से मात्र 37.8 प्रतिशत कृषक परिवार लाभान्वित हो रहे हैं। 62 प्रतिशत कृषक परिवारों को योजनाओं के विषय में जानकारी नहीं है।

सरकार द्वारा प्रदान कराई जाने वाली योजनाओं से मात्र 17 प्रतिशत कृषक परिवार लाभान्वित हुए हैं।

स सरकार द्वारा प्रदान कराई जाने वाली योजनाओं से सबसे अधिक पिछड़ी जाति से गन्ना कृषक परिवार 45 प्रतिशत लाभान्वित हुए हैं और सबसे कम अनुसूचित जाति से मात्र 35 प्रतिशत कृषक परिवार।

$>$ शोध क्षेत्र में गन्ना मिल द्वारा प्रदान कराई जाने वाली योजनाओं से 91 प्रतिशत कृषक परिवार लाभान्वित हो रहे हैं तथा 9 प्रतिशत कृषक परिवारों को योजनाओं की जानकारी नहीं है।

सुझाव :- वर्तमान शोध अध्ययन से स्पष्ट है कि शोध क्षेत्र में गन्ना उत्पादन हेतु सरकार व गन्ना मिल द्वारा विभिन्न योजनाये उपलब्ध करायी जा रही है जिसमें गन्ना मिल द्वारा योजनाओ का लगभग 38 प्रतिशत व सरकार द्वारा योजनाओ का कुल 17 प्रतिशत कृषक परिवारो को ही लाभ मिल पा रहा है अतः शोध क्षेत्र में गन्ना कृषक परवारो को सरकार व गन्ना मिल के द्वारा गन्ना उत्पादन हेतु विभिन्न योजनाओ के प्रति जागरूक करने की अति आवश्यकता है। उपरोक्त सभी नीतियो/योजनाओ का वितरण सभी जातियो में समान रूप से करने की आवश्यकता है तथा योजनाओ को ग्रामीण स्तर तक सभी गन्ना कृषक परिवारो तक पहुँचाने के तरीके को सरल व सबकी पहुच में लाने की आवश्यकता है। जिससे गन्ने के उत्पादन को अधिक बढाने में गन्ना कृषको की सहायता की जा सके।

\section{संदर्भ सूची}

- अग्रवाल एन०एल० : भारतीय कृषि का अर्थशास्त्र (1983), राजस्थान हिन्दी ग्रन्थ अकादमी, जयपुर।

- कुमार एस, 2003 गन्ना विश्लेषण, दीप और दीप प्रकाशन दिल्ली।

- गन्ना विकास भवन मेरठ।

- गन्ना विकास परिक्षेत्र मेरठ।

- गन्ना विकास परिक्षेत्र मवाना।

- गन्ना विकास परिक्षेत्र सरधना।

- गन्ना विकास परिक्षेत्र सिम्भावली।

- गन्ना विकास परिक्षेत्र धौलाना।

- गन्ना विकास परिक्षेत्र हापुड।

- पाण्डेय ए0पी० 2007,ग्रामीण भारत का गन्ना उ़द्योगों में योगदान।

- सनाल एन (2008) भारत में गन्ना उत्पादन योजना।

- संयुक्त कृषि विकास मण्डल मेरठ।

- सिह एस0 पी0, 2007, उ0प्र० में चीनी मीलों का आर्थिक आंकलन।

- www.gannavikasbhavan Lucknow up 